Boletim IG. Instituto de Geociências, USP, V. 5: $57-64$ - 1974.

\title{
MAGNETISMO ANÕMALO DE ALGUNS DEPÓSITOS DE FERRO SUPÉRGENOS DE MINAS GERAIS
}

\author{
por \\ André Davino \\ Instituto de Geociências, USP
}

\begin{abstract}
Cangas and other types of supergene iron deposits show magnetic anomalies stronger than that corresponding to the big mass of itabirite and hematite from the Itabira ferriferous district, in Minas Gerais. The Magnetic behaviour of these deposits is not related to their content of magnetite, but, most problably to the content of maghemite, a ferriferous supergene mineral of high magnetic susceptibility.
\end{abstract}

\section{RESUMO}

As cangas e outros tipos de depósitos de ferro supérgenos apresentam anomalias magnéticas muitas vezes mais intensa do que às correspondentes aos grandes corpos de itabirito e hematita do Distrito de Itabira. O caráter magnético desse depósito não esta ligado a seu teor de magnetita, mas, provàvelmente, à maghemita, mineral de ferro de origem supérgena, de alta susceptibilidade magnética.

\section{INTRODUÇÃO}

Ao curso de prospeç̧ão magnetométrica realizadas em áreas do Quadrilátero Ferrífero e na denominada faixa Nova Era - Itamarandiba, MG chamou-nos a atenção as anomalias magnéticas intensas e irregulares, obtidas sobre cangas e outros tipos de depósitos de ferro supérgenos. Essas anomalias magnéticas deveriam ser, normalmente, menos pronunciadas sobre aqueles tipos de depósitos do que nos itabiritos e nas hematitas, rochas a partir das quais se formam. Achamos, por isso, interessante tentar encontrar um explicação para esse fato.

Padrões de anomalias magnéticas. Procurou-se inicialmente classificar as ocorrências de miné-

- Trabalho realizado com auxflio da Fundação de Amparo à Pesquisa do Estado de São Paulo e do Conselho Nacional de Pesquisas. rio de ferro da região pesquisada, não do ponto de vista petrográfico, mineralógico ou genético,

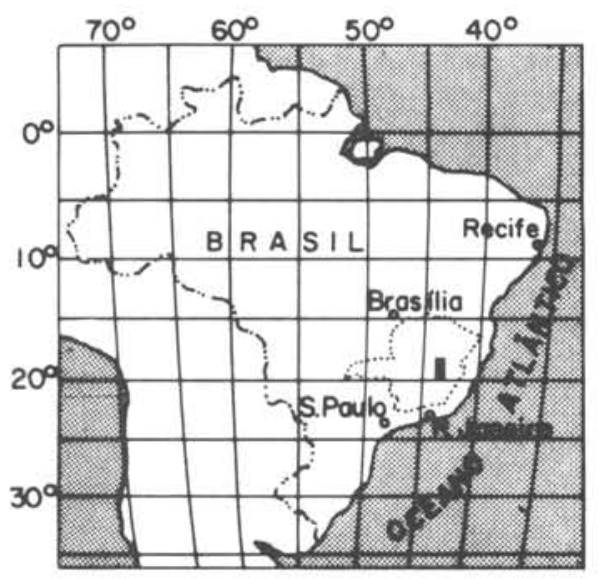

Fig. 1 - Localização da faixa Nova Era - Itamarandiba no Estado de Minas Gerais. 
mas, do ponto de vista da prospecção magnetométrica.

Foram estudadas ocorrências de ferro da faixa Nova Era - Itamarandiba e das jazidas do distrito ferrífero de Itabira. Referências são feitas também a outras jazidas do Quadrilátero Ferriffero.

Existem três tipos bem distintos de padrões de anomalias (fig1) na região em estudo:
10) Anomalias tipo - Cauê, produzidas pelos corpos de itabiritos e hematitas das jazidas situadas no Distrito de Itabira.

20) Anomalias tipo - Boa Esperança, produzidas pelos corpos de hematita $e$ itabiritos magnéticos da faixa Nova Era - Itamarandiba.

30) Anomalias tipo - canga, produzidas

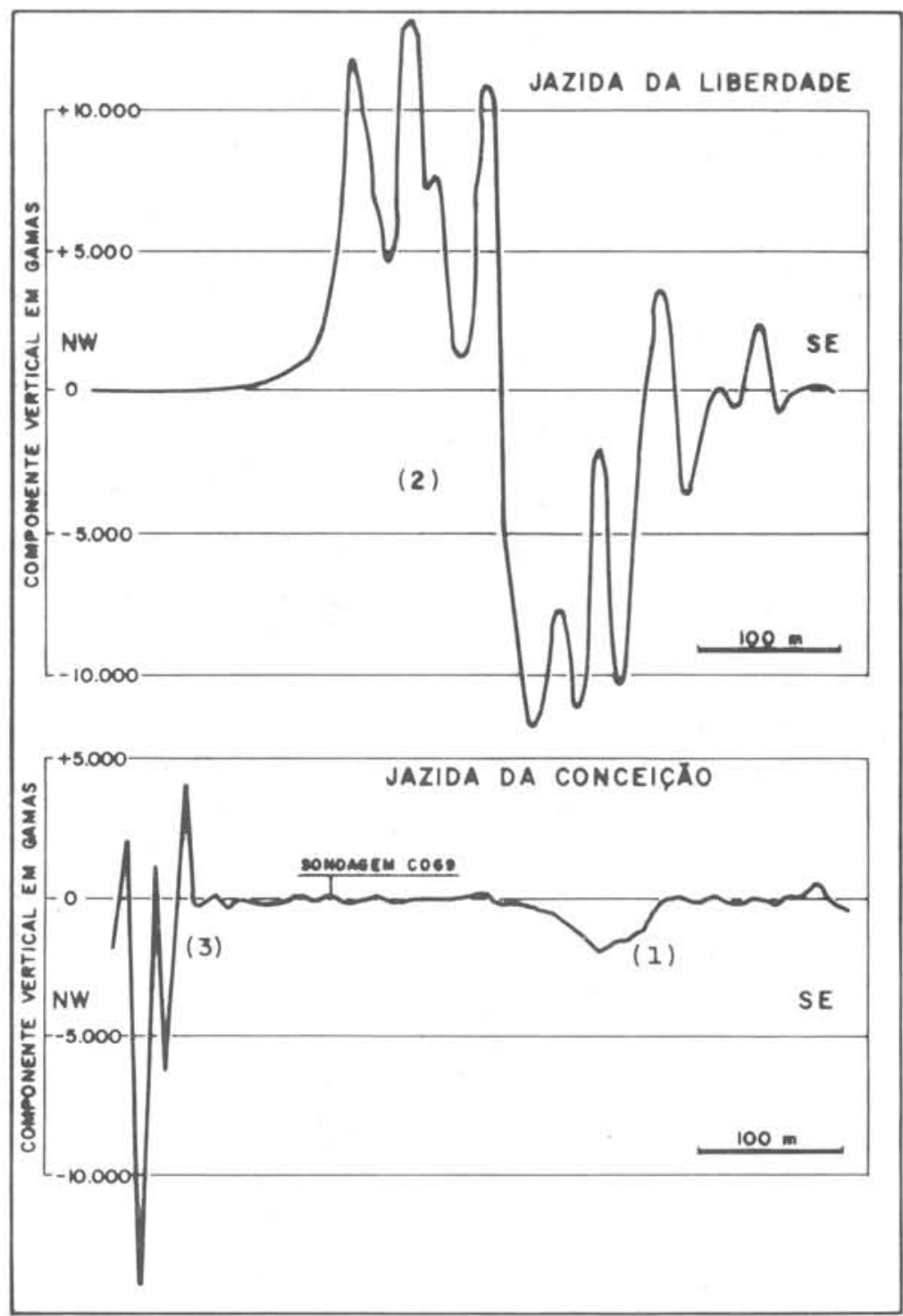

Fig. 2 - Padrões de anomalias magnéticas: (1) tipo-Cauê, (2) tipo-Boa Esperança e (3) tipo-Canga (seg. Davino, 1973). 
pelos depósitos superficiais de minério de ferro, canga, principalmente. Os rolados (vide definição por exemplo, em Dorr e Barbosa, 1963, p. 76) também podem ser incluídos nessa categoria.

Há muitos outros tipos intermediários de padrões de anomalias, mas seria inconsequente para a compreensão da prospeç̧ão e para a interpretação dos resultados uma classificação mais elaborada.

\section{INTENSIDADE DAS ANOMALIAS}

A magnetização das rochas é devida em parte à indução no campo magnético terrestre e em parte à sua magnetização permanente ou remanescente. A magnetização induzida depende primariamente da suscetibilidade magnética e do campo magnetizante; a magnetização permanente depende das transformações pelas quais passou a rocha no decorrer dos tempos geológicos.

Na faixa Nova Era - Itamarandiba afloram rochas fracamente magnéticas: os metassedimentos e rochas graníticas; anfibolitos (Pflug, 1965, p. 39) e quatzitos magnéticos (Pflug, 1965 , p. 29) que ocorrem em menor escala na região devem apresentar magnetismo mais elevado. Essas rochas por sua natureza, apresentam principalmente magnetização induzida, isto é, sob a ação de um campo magnético fixo elas adquirem uma imantação proporcional a esse campo. Pode-se escrever:

$$
\vec{I}=K \cdot \vec{H}
$$

onde $\overrightarrow{\mathrm{I}}$ é a intensidade de magnetização e $\overrightarrow{\mathrm{H}}$, o campo magnético aplicado, ou seja, o campo magnético da Terra; $\mathrm{k}$ é a suscetibilidade magnética volumétrica da rocha.
As rochas das formações ferríferas apresentam não apenas magnetização induzida, mas, principalmente, magnetização remanescente, pois seus constituintes mineralógicos (hematita e outros óxidos e hidróxidos de ferro) são substâncias ferromagnéticas, isto é substâncias que se caracterizam primeiramente, pelos altos valores que podem alcançar sua imantação a partir de fracas intensidades do campo magnetizante e, em segundo lugar pelo fato de conservarem uma parte pelo menos de sua magnetização quando se suprime o campo magnético atuante. São ferromagnéticas a magnetita, a hematita e a maghemita. Nos corpos ferromagnéticos, a imantação não é função definida do campo mag nético presente, pois que nesses corpos a imantação magnética depende também de campos que atuaram anteriormente $\mathrm{e}$, mais genericamente, de todos os tratamentos magnéticos, mecânicos, térmicos e químicos a que foi submetida a rocha.

\section{CAUSAS DO MAGNETISMO}

As medidas magnetométricas nas áreas estudadas permitiram verificar que as anomalias tipo-Cauê são menos intensas que as anomalias tipo Boa Esperança e tipo-canga. A componente vertical das anomalias tipo-Cauê raramente ultrapassa 3.000 gamas, enquanto que essa componente comumente atinge mais de $\mathbf{2 0 . 0 0 0}$ gamas nas anomalias tipo-Boa Esperança e tipocanga.

A princípio pensou-se que essas intensidades pudessem ser explicadas apenas em função do teor médio de magnetita das rochas consideradas, pois, é conhecido o fato da suscetibilidade magnética de uma rocha crescer em função da porcentagem de magnetita. De fato, conforme pode-se notar na tabela 1 há uma diferença marcante no conteúdo de magnetita das hematitas e itabiritos do Quadrilátero Ferrífero e das mesmas rochas do sul da faixa Nova-Era - Itamarandiba, de um lado, e das cangas do Cauê, 
de outro lado.

TABELA 1

TEOR DE MAGNETITA CALLULADO A PARTIK DA ANALLISE QUMMICA DE FEO EM AMOSTRAS DE MINÉRIO DE FERRO DE VARIAS LOCALIDADES DO CENTRO DE MINAS GERALS

\begin{tabular}{|c|c|c|c|}
\hline Local & $\begin{array}{l}\text { No de } \\
\text { Ordem }\end{array}$ & Rocha & $\begin{array}{l}\text { \% eal Peso de } \\
\text { Magnetita }\end{array}$ \\
\hline $\begin{array}{l}\text { Mina Casa da Pedra } \\
\text { Dintrito de Congonhan }\end{array}$ & 1 & liematita & $1,6(a)$ \\
\hline Qundrängulo Nora Lima & $\begin{array}{l}2 \\
3 \\
4\end{array}$ & $\begin{array}{l}\text { Itabirita } \\
\text { Itabirito } \\
\text { itabirito }\end{array}$ & $\begin{array}{ll}4 & (\mathrm{~b}) \\
1 & (\mathrm{~b}) \\
1 & (\mathrm{~b})\end{array}$ \\
\hline Quadrângulo D, Bosco & $\begin{array}{l}5 \\
6 \\
7 \\
8\end{array}$ & $\begin{array}{l}\text { Thabirito } \\
\text { ltabirito } \\
\text { Itabirito } \\
\text { ltabirito }\end{array}$ & $\begin{array}{c}7(c) \\
\text { traçou (c) } \\
\text { traçoo(c) } \\
4(c)\end{array}$ \\
\hline $\begin{array}{l}\text { Quadrangulo os Monleva- } \\
\text { de. Piracicaba }\end{array}$ & $\begin{array}{l}9 \\
10 \\
11 \\
12 \\
13 \\
14 \\
15 \\
16\end{array}$ & $\begin{array}{l}\text { Ttabirito } \\
\text { ltabirito } \\
\text { Itabirito } \\
\text { Hematita } \\
\text { Hematita } \\
\text { Henatita } \\
\text { llematita } \\
\text { Hematita }\end{array}$ & $\begin{aligned} 24 & (d) \\
6 & \text { (d) } \\
10 & \text { (d) } \\
0 & \text { (d) } \\
0 & \text { (d) } \\
0 & \text { (d) } \\
0 & \text { (d) } \\
0 & \text { (d) }\end{aligned}$ \\
\hline Jazida Boa Eaperança & $\begin{array}{l}17 \\
18 \\
19\end{array}$ & $\begin{array}{l}\text { Hematita } \\
\text { Hematita } \\
\text { liematita }\end{array}$ & $\begin{array}{l}24 \\
24 \\
15\end{array}$ \\
\hline Culté & $\begin{array}{l}20 \\
21 \\
22 \\
23 \\
24 \\
25\end{array}$ & $\begin{array}{l}\text { llematita } \\
\text { llematita } \\
\text { liematita } \\
\text { liematita } \\
\text { liematita } \\
\text { llematita }\end{array}$ & $\begin{array}{l}13 \\
16 \\
23 \\
17 \\
14 \\
19\end{array}$ \\
\hline Curriola & $\begin{array}{l}26 \\
27 \\
28 \\
29\end{array}$ & $\begin{array}{l}\text { Hematita } \\
\text { Hematita } \\
\text { liematita } \\
\text { ilematita }\end{array}$ & $\begin{array}{l}16 \\
16 \\
17 \\
41\end{array}$ \\
\hline $\begin{array}{l}\text { Jazida do Caué } \\
\text { Itabira }\end{array}$ & $\begin{array}{l}30 \\
31\end{array}$ & $\begin{array}{l}\text { Canga riea } \\
\text { Canga rica }\end{array}$ & $\begin{array}{l}20 \\
19\end{array}$ \\
\hline
\end{tabular}

Exceto (a), (b), (c) - (d), ab unalises foran feltan no labo ratorio de Quinica da C.V.K.D.

(u) sog. Jollsson(1962) p.31

(b) oeg. GAIR (1062) p. J7 (d) oog. HEEVKS (1956) p.29,33
Foram realizadas diversas experiências com a finalidade de separar mecanicamente o material magnético de amostras de itabirito, hematita e canga. As amostras eram moídas, peneiradas e, por meio de um ímã, eram separadas as frações magnéticas das diferentes classes granulométricas. Cerca de 50 amostras foram separadas e assim pôde-se calcular a porcentagem da fração magnética, suposta constituída principalmente por magnetita.

Algumas dessas amostras trituradas foram analisadas químicamente e a porcentagem em peso de magnetita, calculada a partir do teor em $\mathrm{Fe} 0$, mostrou-se sempre diferente daquela calculada a partir da separação por meio de uma ima.

Assim, a título de exemplos, são dados na tabela 2 os resultados dos testes feitos para amostras de hematita de Curriola e Cuité. As amostras foram cuidadosamente trituradas e peneiradas. Utilizou-se a fração das peneiras $\mathrm{Gra}$ nutest entre 60 e 35 USBS (mesh)ou seja 0,250 a $0,500 \mathrm{~mm}$ ou 60 e 32 Tyler.

Mesmo considerando os erros experimentais, as discrepâncias entre a quantidade de ma-

TABELA 2

COMPARAÇÃO ENTRE AS PORCENTAGENS DE MAGNETITA CALCULADAS POR SEPARAÇĀO MAGNÉTICA E POR ANẢLISE QUUMMICA

Local: Curriola

(hematita)

\begin{tabular}{|c|c|c|c|c|}
\hline $\begin{array}{c}\text { Amostra } \\
\text { ne }\end{array}$ & $\begin{array}{c}\text { quantidade da } \\
\text { amostra } \\
\text { (gramas) }\end{array}$ & $\begin{array}{l}\text { quantidade de } \\
\text { material mag- } \\
\text { nético(gramas) }\end{array}$ & $\begin{array}{c}\% \text { "inagnetita" } \\
\text { er peso }\end{array}$ & $\begin{array}{l}\text { \% magnetita } \\
\text { seg. análi- } \\
\text { se química }\end{array}$ \\
\hline $\begin{array}{l}1 \\
2 \\
3 \\
4\end{array}$ & $\begin{array}{l}15,5 \\
29,9 \\
34,8 \\
25,9\end{array}$ & $\begin{array}{l}6 \\
10,1 \\
19 \\
15\end{array}$ & $\begin{array}{l}38,7 \\
33,7 \\
54,5 \\
57,9\end{array}$ & $\begin{array}{l}16 \\
16 \\
17 \\
41\end{array}$ \\
\hline \multicolumn{2}{|c|}{ 1.ocal: Cuité } & \multicolumn{2}{|l|}{ (hematita) } & \\
\hline $\begin{array}{l}1 \\
2 \\
3 \\
4 \\
5 \\
6\end{array}$ & $\begin{array}{r}272,0 \\
26,5 \\
53,0 \\
47,5 \\
31,2 \\
61,0\end{array}$ & $\begin{array}{l}18 \\
9,9 \\
14 \\
13 \\
19,5 \\
20,5\end{array}$ & $\begin{array}{r}6,6 \\
33,3 \\
26,5 \\
27,3 \\
62,5 \\
33,6\end{array}$ & $\begin{array}{l}13 \\
16 \\
23 \\
17 \\
14 \\
19\end{array}$ \\
\hline
\end{tabular}


terial magnético separado mecanicamente e a calculada a partir da análise química de $\mathrm{Fe} 0$ são grandes e indicam que, além de magnetita, outros minerais podem ser responsáveis pela intensidade das anomalias magnéticas.

Nos trabalhos publicados pelos geólogos do USGS e DNPM sobre a geologia e recursos minerais do Quadrilátero Ferrífero, alguns chegaram a focalizar a questão concernente ao caráter megnético de certos minerais de ferro supérgenos.

Gair (1962, p. A-35) na descrição petrográfica do Itabirito Cauê da Quadrícula de Nova Lima menciona a existência de óxido de ferro magnético. À página $\mathrm{A}-36$, o citado Autor diz que em Itabirito ocreoso predominam óxidos de ferro magnético sendo pequena a porcentagem de magnetita. Gair, no entanto, não identificou o óxido de ferro magnético.

Johnson (1962, p. B-31) separou por meio de uma ímã a fração magnética de uma amostra de itabirito da Quadrícula de Dom Bosco. Um exame ao raio-X dessa fração magnética revelou a presença de magnetita, hematita, traços de quartzo e um mineral de ferro nāo identificado. Maghemita e jacobsita não puderam ser detectadas.

Pomerene (1964, p. D-13) advoga a formação de oxidos de ferro magnéticos por ação do intemperismo ou possivelmente por redução pela luz solar, porque itabirito magnético é raro na subsuperfície.

Dorr (1964) em extenso trabalho sobre os minérios de ferro supérgenos do Quadrilátero Ferrífero afirma (Dorr, 1964, p. 1220) que maghemita, $\gamma-\mathrm{Fe}_{2} \mathrm{O}_{3}$, mineral altamente magnético, é localmente abundante na superfície. Para o referido Autor, por razões desconhecidas, os óxidos hidratados de ferro parecem se desidratar superficialmente para formar uma fina crosta de hematita e maghemita, mas, a poucos centímetros abaixo, nessas localidades, os óxidos são geralmente hidratados. Cocreçð̃es magnéticas coletadas pelo referido Autor nos solos que recobrem filitos na Quadrícula Lagoa Grande foram identificados como maghemita. As causas da formação de maghemita preferencialmente à goethita ou hematita não puderam ser decifradas.

Dorr (1964, p. 1239) no fim de seu artigo recomenda um estudo mais acurado das causas da formação de maghemita e hematita em condições superficiais.

Parece que realmente um mineral magnético formado em condições superficiais seja o responsável em parte pela magnetização das cangas e de outros depósitos de ferro supérgenos. Segundo o relato de Dorr (1964) tratar-se-ia de maghemita.

A gênese e a paragênese da maghemita não é ainda um problema solucionado. A maghemita pode resultar ou da alteração supérgena da magnetita ou provir de outros óxidos de ferro pela ação redutora de matéria orgânica ou pela desidratação da lepidocrosita, $\gamma-\mathrm{FeO} . \mathrm{OH}$ (Deer et al, 1962, p. 77).

\section{ESTUDOS POR RAIO-X E EM SECÇÕES POLIDAS}

Um estudo por raio- $\mathrm{x}$ foi elaborado no laboratório de Mineralogia do Instituto de Geociências da USP pelo Dr. J.V. Valarelli em amostras de cangas do Distrito de Itabira e hematita granular compacta de Boa Esperança. Seç̧̃̃es polidas desses materiais foram estudadas pelo Dr. A.P.Barbour em colaboração com o Professor Dr. J.Moreschi, ambos, também do Instituto de Geociências da USP.

Minério de ferro de Boa Esperança. Foram examinadas 8 seç̧ões polidas. Verificou-se que as amostras estudadas caracterizavam-se por vários graus de oxidação. Alguns grãos estão completamente oxidados; outros, semi-oxidados e outros ainda não-oxidados. A oxidação da magnetita efetuou-se de maneira uniforme em todo o grão, não se notando direçð̃es preferenciais. Os grãos não oxidados, isótropos, com 
refletividade menor do que a da hematita, puderam ser identificados como magnetita. Os grãos semi-oxidados, com ligeira anisotropia e refletividade menor que da hematita, não puderam ser identificados. Os grãos completamente oxidados são de hematita; são anisótropos e mostram refletividade maior do que a da magnetita.

A contagem ao longo de linhas paralelas de duas centenas desses grãos indicam as seguintes porcentagens:

$$
\begin{array}{ll}
\text { grãos não-oxidados (magnetita) } & -10 \% \\
\text { grãos semi-oxidados (? ) } & -20 \% \\
\text { grãos oxidados (hematita) } & -70 \%
\end{array}
$$

Para suplementar os dados ópticos uma amostra do minério de ferro de Boa Esperança foi estudada por difratometria de raio-X. A amostra, após trituração, foi submetida a tratamento prévio em vácuo de $10^{-5} \mathrm{~mm}$ de mercúrio e aquecimento de $385^{\circ} \mathrm{C}$. Com esse tratamento objetivou-se a recristalização da magnetita e da possível maghemita, evitando-se a oxidação do $\mathrm{Fe}^{2+}$. Isto permitiu a obtenção de um diagrama de difratometria mais nítido.

Esse diagrama indicou a presença de hematita, magnetita, maghemita e um outro mineral não identificado.

A comparação dos dados obtidos com o estudo microscópico com luz refletida e de difratometria sugere a seguinte correspondência:

$$
\begin{aligned}
& \text { grãos oxidados } \rightarrow \text { hematita } \\
& \text { grãos semi-oxidados } \rightarrow \text { maghemita } \\
& \text { grãos não-oxidados } \rightarrow \text { magnetita }
\end{aligned}
$$

Nessa comparação a hematita e a magnetita têm determinação óptica segura.

Canga de Itabira. No estudo das secções polidas da canga coletada da Mina do Cauê, no Distrito de Itabira, foi caracterizado um mineral anisótropo (hematita) e alguns grãos de quartzo. Não foi verificado nenhum mineral isótropo nas secções da amostra estudada.
Os estudos dos difratogramas de amostras de canga do Distrito de Itabira não são conclusivos quanto à presença de maghemita. Foram efetuados os seguintes ensaios por didratometria de raio-X:

1) Sem tratamento térmico prévio

a) de um bloco de hematita da canga

b) de cimento da canga

c) da fração magnética de cimento da canga

2) com tratamento térmico prévio, isto é, aquecimento a $385^{\circ} \mathrm{C}$ em vácuo de $10^{-5} \mathrm{~mm} \mathrm{Hg}$.

d) do cimento da canga.

O ensaio (a) indicou essencialmente hematita e impurezas não identificadas.

$\mathrm{O}$ ensaio (b) permitiu verificar a presença de hematita, goethita, e outros minerais não identificáveis por causa da má qualidade de difratograma.

O ensaio (c) consistiu em separar do cimento da canga a parte magnética por meio de um imã-de-mão. 0 diagrama correspondente à porção magnética do cimento da canga é semelhante ao obtido no ensaio (b), mas, com pronunciamento maior das raias da hematita. Estão presentes raias da goethita, quartzo e outros minerais não identificáveis.

0 ensaio (d) indicou: hematita, goethita, quartzo e possivelmente maghemita.

\section{CONCLUSÕES}

$\mathrm{O}$ teor de magnetita das rochas das formações ferrifferas tipo-Cauê, tipo-Boa Esperança e tipo-canga explica em parte as intensidades das anomalias magnéticas. Os itabiritos e hematitas da ocorrência de Boa Esperança contêm um teor mais elevado de magnetita que as rochas correspondentes do Distrito de Itabira, conforme os resultados a partir da análise 
química e estudo em secção polida. Uma parte dos grãos de magnetita de minério de Boa Esperança se transformou em maghemita, que é um mineral também altamente magnético.

As cangas apresentam anomalias de intensidade muitas vezes superiores às dos grandes corpos de itabirito e hematita do Distrito de Itabira. O caráter magnético desses depósitos não parece estar ligado a seu teor de magnetita, mas, provavelmente a um outro mineral de ferro de origem supérgena. De acordo com Dorr (1964, p. 1220) esse mineral seria a maghemita. Os ensaios realizados com difratometria de raio-X em amostras de canga indicaram apenas a possibilidade da existência de maghemita. Como a imantação permanente de um mineral depende dos tratamentos magnéticos, mecânicos, térmicos e químicos a que a rocha foi submetida no tempo geológico é muito possível que outros fatores, além da provável presença de maghemita, contribuíram para a magnetização das cangas.

\section{AGRADECIMENTOS}

Somos gratos aos Geólogos que nos auxiliaram na elaboração deste trabalho: Dr. Aledir Paganelli Barbour, Dr. João Moreschi, Dr. Vicente Antonio Girardi, Dr. Kenkichi Fujimori, Dr. José Vicente Valarelli, colegas do Instituto de Geociências da USP.

\section{BIBLIOGRAFIA}

DEER, W.A., HOWIE, R.A. e SUSSMAN, J. (1962) - Rockforming minerals. vol. 5. Non-silicates, $371 \mathrm{pp}$. John Wiley and Sons Inc. Nova York.

DORR, J.V.N. II (1964) - Supergene iron ores of Minas Gerais, Brasil. Economic Geology vol. 59, no 7, pp. $1203-1240$.

DORR, J.V.N. 2d. (1958) - The Cauê Itabirite. Bol. Soc. Bras. Geol. vol.7, no 2, p. 6162. São Paulo.

DORR, J.V.N. 2d. e BARBOSA, A.L.M. (1963) - Geology and ore deposits of tje Itabira distritc, Minas Gerais, Brasil. USGS, Prof. Paper 341-C, 110 p. Washington.

DORR, J.V.N. 2d., GAIR, J.E., POMERENE, J.B. e RYNEARSON, G.A. (1957) - Revisão da Estratigrafia pré-cambriana do Quadrilatero Ferrifero. DNPM, avulso 81. Rio de Janeiro.

GOKHALE, K.V.G.K. (1961) a - Studies on the oxidation of magnetite. Economic Geology, vol.56, pp. 963-971. (1961) b - Studies on the oxidation of Goethite. Economic Geology, vol. 56. pp. 1058-1062.

GUILD, P.W. (1960) - Geologia e Recurso Minerais do Distrito de Congonhas, Estado de Minas Gerais. Memória no1, DNPM, Rio de Janeiro.

JAHREN, Ch. E. (1963) - Magnetic Susceptibity of bedded iron-formations. Gephysics.

JOHNSON, R.F. (1962) -Geology and Ore Deposits of the Cachoeira do Campo, Dom Bosco and Ouro Branco Quadrangles, Minas Gerais, Brasil. USGS Prof. Paper 341 $B$, Washington.

PFLUG. R. (1965) - A geologia da parte meridional da Serra do Espinhaço e zonas adjacentes, Minas Gerais. Bol. 226 da DivGeol. e Min. do DNPM, Rio de Janeiro.

POMERENE, J.B. (1964) - Geology and ore deposits of the Belo Horizonte, Ibité and Macacos Quadrangles Minas Gerais Brasil. U.S. Prof. Paper 341-D. Washington. 
REEVERS, R.G. (1966) - Geology and Mineral Resources of the Monlevade and Rio Piracicaba Quadrangles, Minas Gerais, Brazil. USGS Prof. Paper 341-E, Washington.
WALLACE, R.M. (1965) - Geology and Mineral Resources of the Pico de Itabirito District Minas Gerais Brazil. Geol.Survey Prof. Paper 341.F. Washington. 